\title{
Factors affecting women's empowerment in disaster risk governance in Sri Lanka
}

\begin{abstract}
:
Women have been disproportionately affected by disasters due to their vulnerabilities and low coping capacities. Increasing trend of natural disasters demands innovative and effective disaster risk reduction and resilience mechanisms to minimize their disproportionate effects from future disasters. Women's empowerment in risk governance has been recognized as such innovative mechanism to reduce disaster risks among women and the society through resilience building. However, limited evidences have been presented on how to achieve their empowerment in disaster risk governance.

Hence, this paper aims to explore the challenges that prevent their empowerment in disaster risk governance structures. The study was conducted in Sri Lanka due to its increasing nature of disaster risks and the status of women's empowerment in risk governance structures. Based on the literature review, a semi semi-structured interview guideline was designed to conduct experts' interviews as the data collection method. Interview results were analysed qualitatively to identify the challenges that limit their empowerment in disaster risk governance and make suggestions to address this issue. Accordingly, twenty challenges were identified and categorised within five broad themes as: legal, institutional, individual, social \& cultural and nature of the job. This study further provides suggestions based on interview outcomes towards resilience building.
\end{abstract}

Keywords: women's empowerment, disaster risk governance, natural disasters, Sri Lanka, governance

Corresponding Author: K.Hemachandra2@hud.ac.uk

\section{Introduction}

Increasing frequency of occurrence of disasters have significant impacts on global affairs in terms of social, economic, political and environmental measures (Seidler et al, 2018). Their impacts are diverse across different communities (Drolet et al., 2015). For example, more deaths have been reported from middle-income and low-income countries (CRED, 2018) and countries where weak institutional and governance structures are operated (Gurmai,2013). Similarly, more women have been affected in disasters than men irrespective countries' socio-economic statuses. For example, higher mortality rates, higher morbidity rates and higher number of victims from violence and harassments have been reported among women and girls than men and boys (K. Alam \& Rahman, 2014; Bradshaw \& Fordham, 2013; Cutter, 2017; Drolet et al., 2015; Enarson \& Chakrabarti, 2009; Islam, Ingham, Hicks, \& Manock, 2014; Kottegoda, 2011; Parkinson, 2011). For example, the death toll of women was four times higher than men in some locations in the 2004 Indian Ocean Tsunami incident (Oxfam, 2005). A similar situation was reported in 1991 floods and cyclone Gorky in Bangladesh reporting approximately 93 per cent of women deaths in the event (Alam \& Rahman, 2017). Another disaster reported from Nepal, during 2015 earthquake with a recorded death rate was 55 per cent among women and girls (Kathmandu Post, 2015). In addition to high 
mortality rates, more health issues have been reported among women and girls in disasters (Islam et al., 2014). Thus, many scholars have identified the gendered nature of disasters (Bradshaw \& Fordham, 2013; Enarson \& Chakrabarti, 2009). Some researchers have identified the reasons for their disproportionate effects of disasters on women due to their physical vulnerabilities, excessive work load, dependence on males in their household decision making (Islam, et al, 2014; Cutter, 2017) and minimum representation of women in disaster risk reduction decision making (Saito, 2012).

Thus, several researchers have emphasised the necessity of empowering women as a strategy to reduce their vulnerabilities in disasters (Kottegoda, 2011; Ginige et al, 2014; Ariyabandu and Wickramasinghje, 2003). Through their empowerment in disaster risk reduction decision making could generate many advantages to women who have been affected significantly from disasters and the whole society (Ginige et al, 2014; Thurairaja et al, 2010). This enables the decisionmaking process to incorporate their needs, specific issues and concerns through women's empowerment. Women empowerment can also be used as a strategy to enhance the quality of the disaster risk governance system through equal participation (Renn, 2012). In addition to researchers, many global frameworks have identified the necessity of empowering women in DRR (UNISDR, 2015; UN, 2015). For example, the Sendai Framework for Disaster Risk Reduction emphasises to empower women in disaster risk reduction measures (UNISDR,2015). However, no evidence is available on how to empower women in disaster risk governance.

Hence, this study aims to propose suggestions on how to empower women in DRG by identifying the factors that affect women's empowerment in DRG. The study begins with a literature review which provides introduction to basic concepts used in the study. The literature reviews also emphasised the importance of women's empowerment in DRG. Then, the methods and methodologies used to achieve study objectives are presented in Section 3. Section 4 presents the results based on expert interview analysis. Section 5 presents conclusions for the study.

\section{Literature review}

2.1. What is women's empowerment (WE)?

The term empowerment has been widely used in psychology and population studies in the $20^{\text {th }}$ century (McWhirter, 1991; Oxaal \& Baden, 1997). Hawxhurst and Morrow (1984) define empowerment as a process of acquiring control of someone's life and supporting others to get control over their lives. McWhirter (1991) presented a feminist perspective in defining empowerment as transformative power. According to Rowlands (1995), empowerment is not limited to giving access to decision making, but it is also about allowing people to perceive women as having abilities and capacities in decision making. Further, he argued that WE should not be limited to psychology but should be considered in diverse fields. Empowerment is a complex phenomenon which needs many factors to assure in the society (Farzana Bari, $2012^{1}$ ). Researchers have shown the benefits of empowering women in an economic context. For

\footnotetext{
1 Bari, F. (1998). Gender, disaster, and empowerment: A case study from Pakistan. E. Enarson, \& BH Morrow, The Gendered Terain of Disaster. Miami, Florida: International Hurricane Center, Florida International University.
} 
example, in the Bangladesh Grameen credit programme, women's financial empowerment has been enhanced significantly (Hashemi, Schuler, \& Riley, 1996).

Many global initiatives have documented WE as a priority for action. For example, the United Nations Conference of Environment and Development (UNCED) Agenda 21 emphasised the necessity of advancement and WE in decision making as a key to sustainable development (United Nations, 1992). In addition, at the Copenhagen Declaration of the World Summit on Social Development (WSSD), declared that one of their main objectives of development should be to empower women to strengthen their capacities.

This study focusses on women's empowerment in disaster risk reduction (DRR) perspective. This is because, women's empowerment in DRR bring multiple benefits to women as well as to the society. Thurairajah et al (2008) define women's empowerment in DRR as the process by which women acquire power to make strategic life choices which overcome their barriers and serves to achieve disaster resilient societies. This study specifically focuses on empowering women in disaster risk governance. In other words, empowering women in disaster risk reduction decision making in the governance structure. Through this measure, the study can contribute to policy making through reducing their vulnerabilities and enhancing risk governance which ultimately benefits towards a resilient society.

\subsection{What is disaster risk governance (DRG)?}

The second concept used in the study is DRG. UNDP defines DRG, as "The way in which public authorities, civil servants, media, private sector, and civil society at community, national and regional levels cooperate to manage and reduce disaster and climate-related risks" (UNDP, 2013). Ikeda and Nagasaka (2011) define it as "An emergent version of integrated risk management that is tailored or directed to enhance a coping capacity under high complexity and uncertain conditions of post-industrial society". According to these definitions, DRG assures the availability of capacity and resources to prevent, prepare for, manage and recover from future disasters. Good governance ensures delivery of efficient and effective outcomes of economic, social and environmental decisions (Rogers and Hall, 2003). Multi-stakeholder participation is a key consideration of risk governance (Haigh \& Amaratunga, 2010; Renn, 2012) to get inputs and concerns of different stakeholders when making decisions for uncertain conditions (Renn, 2012) and to minimise negative results of trade-offs when making decisions under high risks and uncertain conditions (Ikeda \& Nagasaka, 2011; Renn, 2012). Hence, this study refers to disaster risk governance as the system that assures capacity and full participation of stakeholders in national disaster management structure to reduce disaster risks and enhance resilience. Among these stakeholders, women are considered as one of the most important stakeholders in DRG and following section explains their role in DRG based on the literature review.

\subsection{Importance of women's empowerment in disaster risk governance (DRG)}

Women play a significant role as important stakeholders within gendered disaster contexts. Many researchers highlight women's capacities in resilience than vulnerabilities in disasters (Drolet et al., 2015; Saito, 2012). Hence, some researchers suggest considering disasters as an opportunity 
to prove their capacities (Drolet et al., 2015). For example, the role of women can also be identified when assessing and analysing disaster risks. Women are considered as agents for change within their communities and even in the wider spectrum (Luke \& Munshi, 2011; Morchain \& Kelsey 2016). Luke and Munshi (2011) explains that with their economic empowerment, they get high opportunity to take household decisions specifically among women in some low casts in India. Their unique skills, qualities and expertise benefit to enhance quality governance (Gurmai, 2013) through accuracy and transparency in the decision-making process (Kaur, 2016). Rezazadeh (2011) presented the role of women in achieving good urban governance in Iran by minimizing corruption. out their skills and experiences for effective DRR (Ariyabandu, Wickramasinghe, \& 2003; Kottegoda, 2011; Thurairajah, 2008).

The importance of DRG has increased with frequent hazards (Renn, 2012). Women as stakeholders are necessity for effective disaster risk governance mechanism (Saito, 2012; Reyes, 2016; Ginige et al, 2016; Hemachandra et al, 2018). The absence of women in disaster planning has revealed many issues during the response and recovery stages. For example, a study by Saito (2012) shows that the limited participation of women in planning in local authorities for disaster prevention in Japan created many issues for women who were affected by earthquakes.

Even though the importance of women's empowerment in disaster risk governance structures has been emphasised by many researchers, limited evidences are available on how to empower them in disaster risk governance structures. Hence, this study has been conducted to fill this literature gap as well as to provide inputs for policymaking by suggesting necessary actions to be taken to deliver study objectives. The next section presents the methods and methodologies used to conduct the study in achieving its objectives.

Disaster risk governance in Sri Lanka with local governance ${ }^{2}$

\section{Study methods and methodologies}

The study conducted a detailed literature review using books, peer-reviewed journal articles, official reports and official websites. The literature review was conducted to identify the research gap in the disaster literature and to determine a suitable study methodology. In addition, literature review helped to identify theoretical background and concepts related to women's empowerment and disaster risk governance. Based on the literature review, semi-structure interview guidelines have been developed to identify the factors that affect WE in disaster risk governance in Sri Lankan context. The semi-structured interviewed consisted of 15 questions to collect qualitative data on status of women empowerment in disaster risk governance and the factors that affect their level of empowerment in disaster risk governance structure ion Sri Lanka.

Using the semi-structured interviews, nine semi-structured expert interviews were conducted during November 2017. The interviewees were selected based on their experience and expertise

\footnotetext{
2 Iglesias, G., Arambepola, N. M. S. I., Rattakul, B., \& Center, A. D. P. (2009). Mainstreaming disaster risk reduction into local governance. In National Symposium on Creating Disaster Free Safer Environment. Colombo: National Building Research Organisation and Ministry of Disaster Management and Human Rights.
} 
in the field. While selecting experts the institutions involved in Sri Lankan disaster risk governance structure was considered. Accordingly, 2 officials from the Disaster Management Centre, 1 officer from the Department of Irrigation, 1 officer from the National Building Research Organization, 1 District Secretariat, 2 Divisional Secretariats, 1 District Disaster Management Coordination Director and 1 academic were interviewed. The face to face interviews were continued between 35 to 90 minutes. All interviews were recorded using a voice recorder and then manually transcribed into a word document. The transcribed data were analysed using NVivo version 12 software to conduct qualitative analysis. Transcribed data were coded to identify the main themes and their relationships and presented as using thematic analysis.

The reason for selecting Sri Lanka as the study area due to its hazard profile and its present status of women in disasters. Sri Lanka is an island located in the Indian Ocean with a land area of $65,610 \mathrm{~km}^{2}$ with proximity to India to the north and the Bay of Bengal to the North East. Its average Gross National Income per capita at current US\$ is 4,060 which identifies it as a upper middle-income country (The World Bank, 2018). Its average life expectancy at birth is 75.5 years, while expected years of schooling is 13.9 years for individuals (specifically 14.1 years for female and 13.6 years for males) in 2017 (HDI, 2018). In terms of natural hazards, it experiences all forms of hydrological, atmospheric and geological hazards due to its geographic location and other socio-economic activities (Jayawardane, 2006). During 1900- 2020 more than 39,900 deaths were caused by natural hazards in Sri Lanka. This includes deaths caused by the Indian Ocean Tsunami in 2004 (EM-DAT, 2020). The most common natural disasters in Sri Lanka are floods and droughts (Jayawardane, 2006). Within the last three decades, Sri Lanka has been affected either by annual floods or droughts or by both disasters annually (EM-DAT, 2017). In the recent past the threat of landslide have been added to disaster profile in Sri Lanka. Of 25 districts, more than 10 districts have been identified as landslide-prone districts in Sri Lanka (NBRO, 2017). The gendered nature of disasters has been evidenced from the Sri Lankan disaster profile as well. For example, 2004 Indian Ocean Tsunami killed in overall four times as many women than men in Sri Lanka (Kottegoda, 2011). Similarly, many women have been affected from floods and droughts in Sri Lanka (OCHA, 2016b).

\section{4. results}

\subsection{Present status of Women's empowerment in Sri Lanka}

There are many indicators used to measure the level of women's empowerment. One such indicator is the Gender inequality index which is measued as a part of hHuman Development Index by UN. Even though Sri Lankan Human Development Index (HDI) represents the high human development category standing at $71^{\text {st }}$ place in 2019. its Gender Inequality Index (GII) for Sri Lanka is 0.380 ranking $86^{\text {th }}$ place out of 160 countries in 2019 . This index represents a combination of three aspects: reproductive health, empowerment and economic activity. This is used to measure level of empowerment, the share of parliamentary seats held by women, and attainment in secondary and higher education by each gender.

The level of empowerment is measured using the share of women in female seats in parliament 
and population with secondary education. Accordingly, the share of women in parliamentary seats is 5.8 per cent in 2019 in Sri Lanka which is far behind the average of South Asia ${ }^{3}$ and world average. The level of education to secondary level among adult women in Sri Lanka is 82.6 per cent compared to 83.1 per cent of males. There are some more indicators show the level of inequality for women in Sri Lanka. In terms of socio- economic indicators of empowerment too represent an inequality for women in Sri Lanka. Labour force participation rate among women to men is 34.9: 72.2 per cent in ages 15 and older. Further, the share of females employed in senior and middle management is just 24 per cent and mandatory paid maternity leave is only for 84 days. These indicators demonstrate the overall level of women's empowerment in Sri Lanka (UNDP, 2018).

This demonstrates the present status of women in employment and decision-making positions in Sri Lanka. According to De Alwis and Bombuwela (2013), the status of women in planning, decision making and policymaking, either in the private or public sector, is very low. This demands strong policy changes to empower women more in governance for overall development in Sri Lanka (Herath, 2015). In particular, the empowerment of women in governance is mostly discussed in terms of political leadership. Little has been studied of their role in the domain of disaster risk governance (Hemachandra et al, 2018). Sri Lankan women have shown advancements in access to better educational opportunities when compared to many other developing countries. Even though there is an increase of women in the public and private sector in terms of number, many women hold minor positions, earning low incomes (Herath, 2015). According to Herath, most Sri Lankan women in the workforce, as well as the community, do not hold equal status and equal economic opportunities as their peers in other countries. They are subjected to many decimations at the workplace in terms of sexual harassment and glass ceilings.

According to expert 1 and 3 , explained the status of women empowerment is minimum at the decision-making level in their organizations.

\subsection{Sri Lankan disaster risk governance structure}

The Sri Lankan administrative structure comprises the central government, the provincial government and the local government. The central government comprises ministries, district secretariat offices, divisional secretariat offices and Grama Niladhari (GN) which is the lowest administrative officer in the Central Government Structure in Sri Lanka. Provincial government comprises the governor, provincial council and the chief minister. The local government is also known as the local authority which comprises municipal councils, urban councils, and pradeshiya sabha (this comes under the Provincial Councils in the Local Government System in Sri Lanka).

The Sri Lankan disaster management system comprises the central government structure as the mandated structure. Both provincial and local government institutions are not directly involved in disaster management, since it is not their mandated duty. The national disaster management

\footnotetext{
3 South Asia female seats in parliament is $17.1 \%$ where the world average is $24.4 \%$, India $11.7 \%$, Pakistan $20 \%$. Source: (UNDP, 2019 http://hdr.undp.org/sites/all/themes/hdr theme/country-notes/LKA.pdf
} 
system comprises the National Council for Disaster Management (NCDM), the Ministry of Disaster Management, Disaster Management Centre (DMC), line ministries, four technical agencies, District Disaster Management Coordination Units (DDMCU), district and divisional secretariat offices and GNs. The four technical agencies are the Department of Meteorology, Department of Irrigation, National Building Research Organization and National Disaster Relief Centre (Ministry of Disaster Management, 2014).

The NCDM operates as the supreme body for disaster management in Sri Lanka under the Disaster Management Act No 13 of 2005. It is chaired by the Honourable Excellency the President and the Prime-Minister acts as the Vice-Chairman. Also, 20 ministers from related ministries, chief-ministers of each provincial council, leaders and five other members from the opposition party and the Secretary to the Council. The Council is responsible for formulating a national policy and programme on the management of disasters in the country, to prepare and formulate the National Disaster Management Plan and National Emergency Operation Plan based on the national policy and programme and so on. In addition to the Act, the National Policy on Disaster Management was presented in 2010 to provide details of all arrangements, mechanisms, responsibilities, with time frameworks through actions and principles towards expected outcomes of disaster management in Sri Lanka.

\subsection{Present status of Women's empowerment in disaster risk governance structure in Sri Lanka}

Section 11 of the policy highlights multi-dimensional aspects of disaster management in Sri Lanka recognizing multi-hazard, multi-phase, multi-sectors, multi-stakeholders, multi-locality and multitemporal nature. Its $13^{\text {th }}$ section emphasises equality, diversity and inclusion of marginalized groups and ensures gender equality and WE and includes girls. In addition, the Policy Framework and National Plan of Action to Address Sexual and Gender-Based Violence in Sri Lanka is also related to women affected by disasters in Sri Lanka. Sri Lanka Comprehensive Disaster Management Programme (SLCDMP) also mentions an enabling environment for gender and disability mainstreaming to address long-term gender needs specifically concerning disasters in Sri Lanka. The Women's Charter is another legislative document which is related to women's rights in Sri Lanka.

Experts revealed the necessity of women's empowerment in DRG due to many reasons. Their experience in working with family and other socio-economic actors is one such reasons why they need to be empowered in DRG. Their engagement is very important for preparedness and planning stage because their thoughts are important when selecting evacuation routes, evacuation centers and so on. Lack of women representation in these decision-making levels have led to create many issues in evacuation centres. For example, security for young girls and women, lack of sanitary facilities, many unwanted relationships, violence have been named by experts. According to many experts, Muslim women prefer to deal with women officers than men officers at the evacuation centers as well as other post disaster measures. Many experts highlighted that women's commitment is in disasters. Most women officers in the lower level of the disaster risk governance structure perform well in implementation activities. This is because 
specially they consider the impacts of disasters with a sensitive mind compared to men in disaster risk governance.

Another fact highlighted by expert is that the level of acceptance to women officers are higher at village level. When women officers engage in village level disaster management programme, more women have been attracted. They consider these officers as role models and made them easy to communicate their interests, needs and difficulties than men. Especially young women and girls are reluctant to actively engage in village level programme because of confidence issue. There, the women in disaster governance structure can motivate them to be able to take their active participation and to raise their voice as agents of the society. Another importance of women in DRG is that they are independent decision makers. Experts revealed that women value their prestigious status or dignity than short term benefits. Therefore, they fear of being accused for corruptions and engage in dirty politics. There are some evidences in Sri Lankan disaster governance structure where women have played a strong leadership in disaster governance structure. One of the former Director General of the DMC in Sri Lanka was a woman. She was a very determined character and made many decisions which are practiced even today as sound decisions.

However, such higher positions are very limited in Sri Lankan DRG structure. According to another expert, there are only two women working at the highest decision-making level in the DMC in Sri Lanka as a Director and Assistant Director. All other Directors and Assistant Directors are men at the Centre. A similar situation was reported from all other related technical agencies such as Department of Meteorology, NBRO, Irrigation Department and National Relief Service. Instead, most women in the DRG governance structure engage in implementation stage than decision making level. Many women officers engage in the lower levels of the national disaster management structure representing Divisional Secretariats, Relief officers, Grama Niladhari officers' level in Sri Lanka. In Sri Lanka, there are 25 District Disaster management Coordination Units and 25 directors have been appointed. Except one instance, throughout the time, all units have been coordinated by male directors. Only one lady Director was appointed who fought for the position with strong academic background by convincing the interview panel. The above evidence shows the status of women empowerment in DRG is at a low level due to many reasons. Semi structured interviews with experts revealed following as the reasons or factors for their level of empowerment in DRG in Sri Lanka.

\subsection{Challenges for the women's empowerment in disaster risk governance in Sri Lanka}

This section presents the 20 challenges identified within five categories based on their similarities as "Legal"; "Institutional"; "Individual characteristics"; "Social and cultural considerations" and "Nature of the job" as presented in Figure 1). for WE in DRG in Sri Lanka based on expert interviews.

Figure 1 Challenges identified for the women's empowerment in disaster risk governance in Sri Lanka 


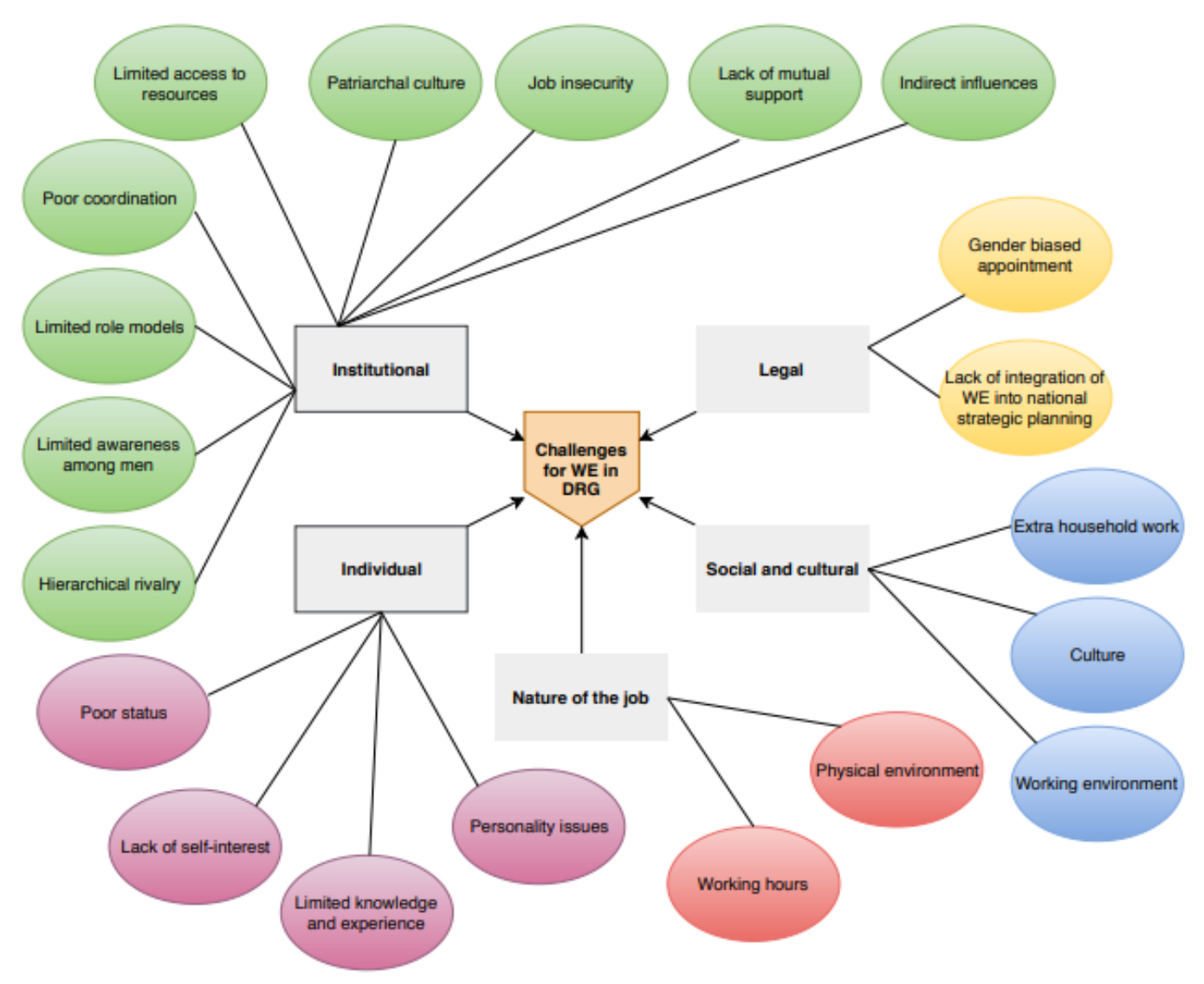

\subsubsection{Legal}

Two challenges categorised within the legal category are gender-biased appointments and lack of incorporation of gender into the country's national strategic plan.

\section{i. Gender biased appointments:}

According to experts interviewed, gender-biased appointments were strictly followed in most government institutions related to disaster management in Sri Lanka in earlier periods. For example, until 2000, women were not appointed to the Department of Irrigation as Engineers or officers. Especially, when appointments are made for higher positions in disaster management, the authorities made sure to give preference to men over women. According to experts, the main reason is maternity leave for women. During their maternity leave, another person needs to cover their duties for the statutory paid maternity leave for women of 84 days.

Another reason for gender-biased appointments is the nature of the job. Jobs related to disaster management require full-time availability and visits to hard geographical locations. Nevertheless, due to the unavailability of men and/or low interest among men, most institutions had to appointment women in more recent periods. Even so, many of these appointments are to lowerlevel jobs, implementing policies and decisions rather than planning and decision-making. As a solution, experts proposed to have certain rules and regulations in institutions to allocate a quota for women in appointments especially to higher positions. Currently, there is no quota system for making appointments to the national governance structure. This makes it difficult to get an appointment in all national government organizations equally. 


\section{ii. Lack of incorporation of gender into the national strategic plan:}

Another major legislative barrier is limited attention to gender and WE in decision making through identifying and integrating gender in the national strategic plan. Even though Sri Lanka ratified the UN Convention on the Elimination of All Forms of Discrimination Against Women (CEDAW) in 1981, there is a need to take serious measures to achieve the stated objectives through legal and administrative provisions. At the time, they established the Women's Charter under the Ministry of Women's Empowerment and Social Welfare. However, the name of the Ministry has changed frequently and now it is named the Ministry of Women and Child Affairs and Dry Zone Development. This indicates that the WE has been disappeared from the legislative system. According to experts, the Women's Charter also focuses on achieving equality rather than empowering them. The Chamber focuses on political and civil rights, rights within the family, right to education and training, right to economic activities and benefits, right to health-care and nutrition, right to protection from social discrimination and right to protection from gender-based violence. Even in the Women's Charter, WE is stated in only two places. The suggestions made by experts were to create a strong link to the National Strategic Plan for WE in the governance structure, through appropriate legal and administrative measures. They believe that unless there are strong legislative and administrative measures placed in the system, women's empowerment in the governance structure will not be achieved.

\subsubsection{Institutional:}

Nine challenges were identified based on experts' interviews within institutional settings: limited awareness among men in institutions; limited availability of role models; poor coordination; limited access to resources; patriarchal organizational culture; indirect influence on women; job security; hierarchical rivalry and low mutual support.

\section{iii. Limited awareness among men in the organizations}

Many experts agree that women face many forms of difficulties and injustices in the workplace. However, they remain silent due to many reasons. For example, they lack confidence about the system and whether this will give a solution or whether it will be another type of harassment. Sometimes, such harassments or difficulties are used to criticise or make claims against women. Therefore, women do not want to reveal these types of issues in front of everyone. Their silence leads to miscommunication of difficulties and injustices encountered by women without them being addressed. This discourages women to talk and express their requirements. The suggestion made by experts is to build confidence among women and raise awareness by campaigning through targeting both men and women in organizations, and furthermore, to secure the system for a safer organization culture.

\section{iv. $\quad$ Limited role models}

Another challenge identified by experts is limited role models. Role models in governance can empower women towards strong leadership and decision-making power. A very limited number of strong role models are identified within the governance structure. According to experts, such role models are not only important to the organizational structure itself but important for society. 
Role models always motivate others to realize their capacities, skills and achieving their demands. Hence, the limited availability of role models hinders their empowerment within the governance structure. Good role models depend on experience, leadership quality and confidence. There are many instances of women exercising power through their leadership skills. For example, the Former Director-General of the Disaster Management Centre in Sri Lanka was a woman with strong leadership skills, strong decision-making and influencing power. Some of her decisions are functioning well even today.

Therefore, the suggestion made by experts is to build such role models through building their confidence, skills and experience in the system. Capacity building programmes and training can be further recommended.

\section{v. Poor coordination}

Another challenge identified by experts is poor coordination between institutions. The government and non-governmental organizations (NGOs) conduct many training programmes to empower women at different levels. However, during a disaster, the government interferes and takes over all decisions without giving women opportunities to show their capabilities in managing local level disasters. This is mainly considered as an issue related to poor coordination between national and local level officers. Therefore, without allowing the utilisation of their capacities and abilities, enhancing their empowerment would be difficult. Hence, many experts suggest establishing proper coordination between government and NGOs, to update their contributions towards empowerment, and accordingly create opportunities for women in administration.

\section{vi. Limited access to resources}

According to experts, resource limitation is another barrier for WE in DRG. Most women do not have the same rights to use resources compared to men in organisations. The situation is further complicated by their roles as lower-level officers. Resource allocation in organizations is similar to resource allocation in households or at the community level. Access to resources at the household level for women is comparatively low. Women in the higher-level hierarchy have some access to resources compared to lower-level officers. According to experts, many men in the higher levels of the hierarchy have access to resources and opportunities in many different ways. Similarly, they demand more resources compared to women. Experts further reveal that women officers are used to working with minimum facilities and not trying to access further resources. This resource limitation hinders their opportunities to link with the rest of the world, to enhance their level of knowledge and minimizes their skills and capacities. Therefore, the suggestions made by experts is to assure resource allocation to be equal among both men and women in organizations. Further to make women aware regarding their right to claim resources and opportunities.

\section{vii. Patriarchal organizational culture}

Patriarchal culture is prevalent in many government organizations. Experts highlighted that many male officers in government organizations dominate the organization and its decision making. Some officers, as well as politicians, let down women officers accusing them of being less committed employees and unable to perform like men. Such cultures discourage and hinder 
women in decision making towards maximum contribution. Experts suggest creating awareness among officers as well as at the community level on the importance of WE towards risk governance and more resilience. They also suggest introducing a quota system for appointments.

\section{viii. Indirect influences in the organization}

Another challenge identified by experts is the indirect influence on women in the risk governance structure. According to them, women use some sorts of influences for their benefits. For example, women take some financial dependence or work dependence on male officers which reduce their independence in the institutional setting. Their empowerment within institutional setting become problematic. Another issue identified by experts is that most higher-level officers do not give opportunities to use their powers. They simply give orders to be followed rather than empowering women to perform their duty within rules and regulations.

For example, one expert revealed that an administrator was introduced to a project by her superior. Her role was to take a decision regarding the project. However, the decision was made by her superior. In this example, she was strong enough to make her own decision but most women will not take such decision on their own.

Besides, there is some level of political influence where the women administrators or officers cannot take their own decisions which limits their empowerment in governance. In other instances, women are limited by their deprived status or destitute condition. Hence, the experts suggest that it is necessary to encourage women in governance through the provision of supportive services such as financial support, childcare support, psychological support and so on.

\section{ix. Job security}

Women in the governance structure are further challenged by their job security. According to some experts, women do not like to decentralize their power assuming that this may affect their job security. They fear to take independent decisions assuming that it will return with some adverse effects on job security, career advancements and especially with transfers.

Further, some women do not trust their fellow officers and hence are reluctant to delegate their functions and authority. In addition, some women officers like to show their power. Hence, they demand fellow officers ask their approval for every activity. This results in delay and inefficient decision making which prevent their empowerment in the governance sphere. The suggestion made by experts is to establish suitable provisions in institutions towards delegation of powers and job security.

\section{x. Hierarchical rivalry}

Another challenge affecting the WE is hierarchical rivalry within institutional structures. Some experts explained how they faced organizational issues when they reached higher positions in the hierarchy. Jealousy among men and women in institutional structures affects WE in governance. According to some experts, competition among positions is strong in institutions. Some experts explain this as the nature of human beings. Rival attitudes among staff affect their decision-making abilities by hiding some information and not adhering to their decisions and are common issues in organizations. This specifically affects women in the organization when the organizational culture is of a more patriarchal type. 


\section{xi. Mutual support}

The lack of mutual support among women administrators in governance creates issues for women in institutions. This interrupts their mutual support towards a common goal and hence end with a competition. Rather than working as a team, they prefer working in isolation or competitively. Mutual support is similarly influenced by hierarchical rivalry and patriarchal culture. According to experts, this can be addressed through promoting group work and group targets as well as through strong leadership.

\subsubsection{Individual characteristics}

According to Figure X.1, the third category of challenges for WE in disaster risk governance is individual characteristics. They are poor status and standard of living; personality; selfinterest, and knowledge and experience.

\section{xii. Poor status}

Most women officers at local level government institutions have a low standard of living and social status similar to that in their communities. Their lower status represents their level of power and voice in decision making in organizations. Since they have limited experience beyond their status level, this results in a lower level of expectation. According to experts, they are happy with minimum standards and facilities which are similar to their daily life. Living in such minimal conditions throughout their lives, does not encourage them to aim for further advancements.

\section{xiii. Personality}

Personality is another challenge for WE as an individual characteristic. Low confidence in themselves, their talents and skills, affects their personality. Many experts agreed that a strong personality can coordinate and manage any condition well. Women with a strong personality can talk effectively and confidently to impress others and engage in effective decision making. However, most women in national governance structure do not show these personal characteristics and lack a high level of confidence. This is also related to organizational culture as well as the individual level of education and skills. In an institution where patriarchal culture exists, the opportunity to develop women's personality is limited. Also, language skills and information technology skills similarly hinder their level of confidence and personality overall. The requirement of capacity building programmes was highlighted by experts to enhance their level of confidence.

\section{xiv. Self-interest}

Empowerment is strongly related to self-interest. The higher the interest, the higher their participation in decision making. Many experts agreed that aspirations to higher positions or extra responsibilities is lacking among many women in governance. Some experts explained this is purely because of their values. For example, giving higher priority for a family commitment. Some women do not like to take extra responsibility and would like to enjoy their freedom. According to them, it is a choice between professional and personal life. Thus, they engage in easy or routine 
jobs in lower positions rather being in administration. Furthermore, some women are not interested in further advancement or career development due to their family background. For example, a strong financial background in the family diminishes their interest. Similarly, when a spouse or partner is busy with work, women deliberately sacrifice their work time and stick to minimum working hours. A different opinion is revealed by some other experts pointing out that job dissatisfaction has negative impacts on active engagement.

\section{Knowledge and experience}

Even though women have the subject knowledge, their social skills and experiences are identified as poor. Knowledge related to disaster management, especially among ground-level officers, is limited. Hence, their concerns and decisions are limited to more local and lower standards due to limited knowledge. Most officers have educational qualifications which are not related to disaster management. Hence, their limited knowledge and experience make decisions either wrong or not relevant. Some experts pointed out that women in governance are effective in talking nevertheless they are not effective in strategic decision making. Thus, the experts' recommendation was to give them some training for building their capacities in disaster management and governance.

\subsubsection{Social and cultural considerations:}

Two challenges within social and cultural considerations affecting the WE in disaster risk governance are: household workload and culture.

\section{xvi. Household workload}

Culturally, women are expected to provide childcare and household work more than men. Hence, most women officers are expected to perform their household duties while also performing a paid job. Women in lower-level administration especially, are expected to engage in more household work than higher-level officers. For example, many women administrators and community representatives are keen to finish programmes earlier since they have to pick up children from school and take them to extra classes etc. One reason is that they have more freedom and flexibility by working at the local level. For example, GN officers perform their duties at home or their GN offices which are mostly located either in their home or in public places. This helps provide flexible working hours than women working in either divisional secretariat offices or district secretariat offices and similar. Further, their earnings are considerably lower when compared to women in higher ranks in the government. Hence, they do not have the opportunity to get some paid services either to look after their children or do household work. These conditions limit their time for decision making and planning.

A different opinion was expressed by women in higher administration saying that they are mostly free from all household-related work because of unlimited support they receive from their family. Most experts revealed that they get maximum support, especially from their husbands and families to look after their children and performing day to day household work. Their family support has been highlighted as a positive factor for enhancing their empowerment in disaster risk governance. Further, they are in a financially strong position to appoint a paid worker to replace 
their household duties.

\section{xvii. Culture}

According to experts, attitude, caste and religious factors are identified as barriers for participation. For example, unmarried women are not expected to work in the night. Such attitudes limit working capacity in DRG. Sri Lanka has a cultural and ethnic diversity. Caste is a challenge identified by experts. If officers belong to certain casts, the level of acceptance, as well as participation in their programmes, is minimal. Especially, officers of a lower caste or different ethnicity at village level face many challenges when performing their duties. However, the community prefers to accept women officers over male officers. This is mainly because, most participants for training programmes are women including elderly women, women with very small children and young school leavers. These participants feel more comfortable to engage with women administrators rather than men. This works as a positive factor for enhancing women in DRG.

\section{xviii. Environment}

The working environment is identified as a challenge when empowering women in DRG. Especially for women field officers, safety and characteristics of the environment are very significant. When officers feel insecure in the field, their ability to fully engage in DRG is limited. Specifically, different socio-economic statuses and different ethnic backgrounds make officers uncomfortable when going to the field. This limits their ability to empower women in governance and develop their full capacity to work in any condition.

\subsubsection{Nature of the job}

The fifth category of challenges is the nature of the job which has two challenges: working environment and no specific time and availability.

\section{xix. Physical environment}

In addition to cultural factors, physical conditions of the working environment are important for the empowerment of women in risk governance. Women face challenges in accessing different geographical locations,. For example, the number of times women officers have attended was limited due to physical barriers: heavy rain, high elevated areas, no proper means of transportation and so on. Such physical conditions make it difficult or restrict women officers from giving their fullest cooperation in risk governance.

\section{xx. No specific time/ availability}

Before, during, and after a disaster, officers are required to be ready for the 24/7 work schedule. According to some experts, this makes it difficult for women and hence reduces their interest, capacities and abilities, and may hinder their contribution towards their empowerment in disaster risk governance. However, some experts rejected this by pointing out their contribution was very high during past disasters situations in Sri Lanka. For example, all district secretariats and divisional secretariats had to work day and night during recent disasters in Sri Lanka. Many district 
secretariats, divisional secretariats, Sahana officers and GN officers are women. Their contribution was tremendous and there were no differences in working in such situations. Women's contribution was very high and effective in post-disaster management situations in Sri Lanka (Drolet et al., 2015). It is also important to note that this $24 / 7$ availability is essential only where a disaster risk emerges.

\section{Conclusions}

The study recognises the significance of WE in DRG within increasing disasters context. Based on the semi-structured experts' interview, the study twenty challenges in empowering women in disaster risk governance within Sri Lankan context. In addition to these challenges, the study also draws suggestions on how to overcome these challenges when assuring their empowerment in DRG in Sri Lanka based on the experts' interviews. Experts recommendations were classified into three measures as: organizational measures, policy changes and community involvements which are presented in Figure 2 and explained below in detail. The model does not reveal that all measures are equally important. This may need further research to identify their level of importance when prioritising these measures. 


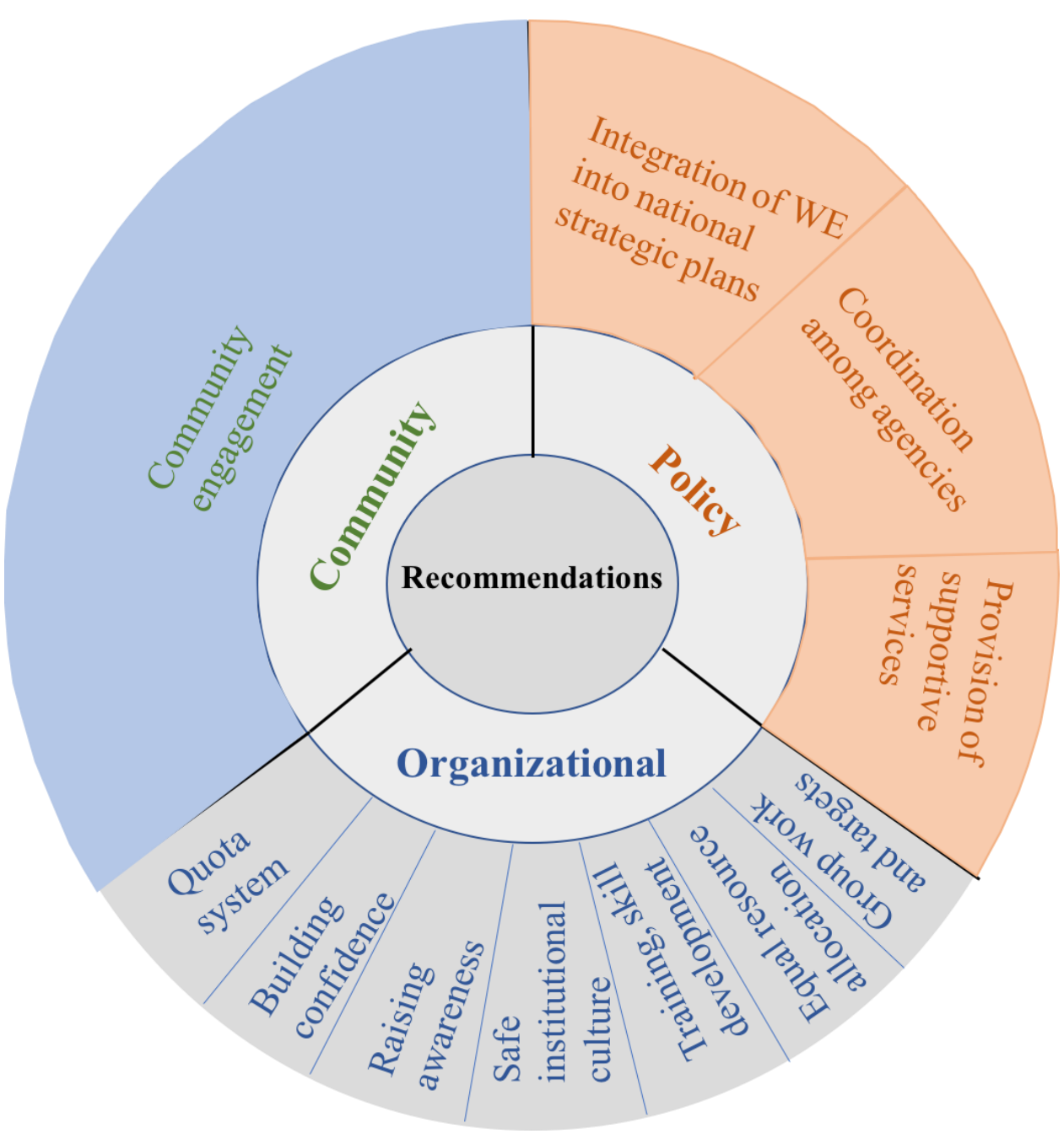

Figure 2 Three-pronged model for addressing the challenges for WE in DRG

Several organizational measures have been recommended by experts to address the challenges. According to experts, creating a quota system can minimize gender biased appointments and overcome or minimize patriarchal organizational cultures within organizations. Building confidence among women officers are expected to develop more role models and personality development. This can also enhance awareness among men in organizations about women's issues through discussions led by women through confidence building. The awareness also helps them to realize the rights of women to access organizational resources. Further this can minimize or overcome patriarchal cultures in institutions. Raising awareness can further helps to overcome difficulties or issues faced by women in institutions. Assuring safe organizational cultures is suggested by experts to address issues related to job security and delegation of powers which are considered as challenges for WE in DRG. Provision of training, skill development and opportunities for women in DRG are strongly recommended by experts. According to experts, such measures help to develop role models and enhance their experiences. In addition, this can help in personality building among women in DRG. Experts opinion was to provide training specifically on disaster management and governance. In addition, such training and skills development should target on addressing challenges related to physical and geographical 
difficulties when working in the field. Furthermore, equal resource allocation must be introduced among men and women as well as among different level of officers in institutions. Promotion of group work and group targets among officers in disaster management related institutions are recommended to create a mutual support among officers which can minimize rivalry and competitions.

The second measure suggested by experts is policy measure. Integration of WE into national strategic plan was suggested as one such innovative policy measure to address the challenges. Further, coordination should be established between government institutions and nongovernment institutions to address the challenge of minimum coordination between agencies which reduces the opportunities for women to demonstrate their capacities. Provision of supportive services towards the enhancement of WE in governance are strongly recommended by experts to minimize indirect influence on women in governance and to reduce their excessive household workload.

The third strategy recommended by experts is the community engagement through community awareness. According to experts, this helps to improve cultural acceptance for women in DRG and to create a safer environment for women work in the field.

As presented above, the study provides reliable and valid recommendations towards women's empowerment in disaster risk governance by identifying their challenges and making suggestions on how to overcome these challenges within Sri Lankan context.

\section{Reference:}

Alam, K., \& Rahman, M. H. (2014). Women in natural disasters: A case study from southern coastal region of Bangladesh. International Journal of Disaster Risk Reduction, 8, 68-82. doi:10.1016/j.ijdrr.2014.01.003

Alam, M. B., \& Rahman, K. A. (2017). Women and Climate Change in Bangladesh: An Analysis From Gender Perspective. Cross-Cultural Communication, 13(8), 7-9.

Ariyabandu, M., Wickramasinghe, M., \& (2003). Gender Dimensions in Disaster ManagementA Guide for South Asia. Retrieved from Colombo:

Bradshaw, S., \& Fordham, M. (2013). Women, Girls and Disasters : A review for DFID Retrieved from https://www.gov.uk/government/uploads/system/uploads/attachment_data/file/236656/w omen-girls-disasters.pdf

CRED. (2018). Economic Losses, Poverty and Disasters 1998-2017 (Issue No 52). Retrieved from

Cutter, S. L. (2017). The forgotten casualties redux: Women, children, and disaster risk. Global Environmental Change, 42, 117-121.

De Alwis, A., \& Bombuwela, P. (2013). Effects of glass ceiling on women career development in private sector organizations-Case of Sri Lanka.

Drolet, J., Dominelli, L., Alston, M., Ersing, R., Mathbor, G., \& Wu, H. (2015). Women 
rebuilding lives post-disaster: innovative community practices for building resilience and promoting sustainable development. Gender \& Development, 23(3), 433-448.

doi:10.1080/13552074.2015.1096040

EM-DAT. (2017). The International Disaster Database. Retrieved from http://www.emdat.be/ pager

Enarson, E. P., \& Chakrabarti, P. G. D. (2009). Women, gender and disaster: global issues and initiatives. Los Angeles, [Calif.];London;: SAGE.

Ginige, K., Amaratunga, D., \& Haigh, R. (2014). Tackling women's vulnerabilities through integrating a gender perspective into disaster risk reduction in the built environment. Procedia Economics and Finance, 18, 327-335.

Gurmai, Z. (2013). Women's role in Good Governance. Paper presented at the Women's role in good governance Challenges, opportunities, best practices and policies Budafest.

Haigh, R., \& Amaratunga, D. (2010). An integrative review of the built environment discipline's role in the development of society's resilience to disasters. International Journal of Disaster Resilience in the Built Environment, 1(1), 11-24.

Hashemi, S. M., Schuler, S. R., \& Riley, A. P. (1996). Rural credit programs and women's empowerment in Bangladesh. World development, 24(4), 635-653.

Hawxhurst, D., \& Morrow, S. (1984). Living our visions: Building feminist community: Fourth World.

Hemachandra, K., Amaratunga, D., \& Haigh, R. (2018). Role of women in disaster risk governance. Procedia Engineering, 212, 1187-1194.

Herath, H. (2015). Place of women in Sri Lankan society: Measures for their empowerment for development and good governance. Vidyodaya Journal of Management, 1(1).

Ikeda, S., \& Nagasaka, T. (2011). An emergent framework of disaster risk governance towards innovating coping capability for reducing disaster risks in local communities. International Journal of Disaster Risk Science, 2(2), 1-9.

Islam, M. R., Ingham, V., Hicks, J., \& Manock, I. (2014). The Changing Role of Women in Resilience, Recovery and Economic Development at the Intersection of Recurrent Disaster: A Case Study from Sirajgang, Bangladesh. Journal of Asian and African Studies. doi:10.1177/0021909614560244

Jayawardane, A. (2006). Disaster mitigation initiatives in Sri Lanka. Faculty of Engineering, University of Moratuwa, Sri Lanka.

Kathmandu Post. (2015). Earthquake: 55 pc of dead are women, children. Retrieved from http://kathmandupost.ekantipur.com/news/2015-05-19/earthquake-55-pc-of-dead-arewomen-children.html

Kaur, D. (2016). The changing concepts of good governance: role and participation of women. International Journal of Socio-Legal Analysis and Rural Development, 1(1).

Kottegoda, S. (2011). Mainstreaming Gender in Disaster Management Policy: Key issues and Challenges in the Asia-Pacific Region Retrieved from http://www.apwwslwngof.org/index.php?option=com_content\&view=article\&id=88

Luke, N., \& Munshi, K. (2011). Women as agents of change: Female income and mobility in India. Journal of Development Economics, 94(1), 1-17.

McWhirter, E. H. (1991). Empowerment in counseling. Journal of Counseling \& Development, $69(3), 222-227$. 
Ministry of Disaster Management. (2014). National Policy on Disaster Management. Retrieved from Colombo, Sri Lanka:

Morchain , D., \& Kelsey , F. (2016). Finding ways together to build resilience. Retrieved from Oxford, UK:

NBRO. (2017). Landslide Early Warning Retrieved from http://www.nbro.gov.lk/index.php?option=com_content\&view=article\&id=115\&lang=en

OCHA. (2016a). Sri Lanka Floods and Landslides: Situation Report 2. Retrieved from OCHA Regional Office, Asia and the Pacific:

OCHA. (2016b). Sri Lanka: Floods and landslides Situation Report No. 2. Retrieved from Resident Coordinator's Office, Sri Lanka:

Oxaal, Z., \& Baden, S. (1997). Gender and empowerment: definitions, approaches and implications for policy: Bridge, Institute of Development Studies.

Oxfam. (2005). The tsunami's impact on women Retrieved from

Parkinson, D. (2011). Gender disaster and violence; literature review. Women's Health Goulburn North East, Victoria.

Renn, O. (2012) Inclusive Risk Governance. 2011-2012 Distinguish Lecture Series, Environmental Scienceand Policy Programme, Michigen State University.

Rezazadeh, R. (2011). Women empowerment and good urban governance in Iran. Asian Social Science, 7(3), 260.

Rowlands, J. (1995). Empowerment examined. Development in Practice, 5(2), 101-107.

Seidler, R., Dietrich, K., Schweizer, S., Bawa, K. S., Chopde, S., Zaman, F., ... \& Khaling, S. (2018). Progress on integrating climate change adaptation and disaster risk reduction for sustainable development pathways in South Asia: Evidence from six research projects. International journal of disaster risk reduction, 31, 92-101.

Saito, F. (2012). Women and the 2011 East Japan Disaster. Gender \& Development, 20(2), $265-$ 279. doi:10.1080/13552074.2012.687225

The World Bank. (2018). Country Profile, Sri Lanka. Retrieved from https://databank.worldbank.org/views/reports/reportwidget.aspx?Report_Name=Country Profile \&Id=b450fd57\&tbar=y\&dd=y\&inf=n\&zm=n\&country=LKA

Thurairajah, N., \& Baldry, D. (2010). Women's empowerment in post disaster reconstruction: Perspectives on policies and frameworks. International Journal of Strategic Property Management, 14(4), 347-361.

UN. (2015). Sustainable Development Goals. Retrieved from https://sustainabledevelopment.un.org/?menu $=1300$

UNDP. (2013). Issue Brief: Disaster Risk Governance Retrieved from New York, USA: https://www.preventionweb.net/files/29974_20121311issuebriefdisasterriskreduc.pdf

UNDP. (2018). Human Development Reports. Human Development Reports. Retrieved from http://hdr.undp.org/en/composite/Dashboard3

UNISDR. (2015). Sendai Framework for Disaster Risk Reduction 2015 - 2030. Retrieved from Geneva Switzerland: http://www.preventionweb.net/files/43291_sendaiframeworkfordrren.pdf United Nations. (1992). United Nations Conference on Environment and Development: Agenda 